\title{
PENGGUNAAN HASHTAG (\#)AKUN TWITTER DIREKTORAT JENDERAL PAJAK DALAM UPAYA MEMBANGUN KESADARAN MEMBAYAR PAJAK
}

\section{Using Hashtag (\#) on Twitter Account of Directorat General of Taxation For Tax-paying Awareness Rising}

\author{
Meladia $^{1}$, M. Nadjib ${ }^{2}$, M. Akbar ${ }^{3}$ \\ ${ }^{1}$ Kementerian Keuangan,(mel.14dy@gmail.com) \\ ${ }^{2}$ Ilmu Komunikasi Fakultas Ilmu Sosial dan Politik, Universitas Hasanuddin,(nadjib.mn@ gmail.com) \\ ${ }^{3}$ Ilmu Komunikasi Fakultas Ilmu Sosial dan Politik, Universitas Hasanuddin(bos_akbar@yahoo.com)
}

\begin{abstract}
ABSTRAK
Perkembangan media sosial terus mengubah cara berkomunikasi. Satu alat yang belum diteliti yang tersedia pada platform media sosial adalah hashtag. Penelitian ini bertujuan mengetahui: 1) tipe dan fungsi Hashtag yang digunakan pada akun twitter @DitjenPajakRI. 2) isi Hashtag yang digunakan pada akun twitter @DitjenPajakRI. 3). Pengaruh penggunaan Hashtag pada akun twitter @DitjenPajakRI untuk membangun kesadaran membayar pajak masyarakat dengan model AISAS. Penelitian ini menggunakan metode deskriptif dengan pendekatan kuantitatif yaitu menggunakan analisis isi kuantitatif dan analisis regresi menguji variable dari hashtag ke dalam model AISAS. Adapun total hashtag yang dianalisis adalah sejumlah 51 hashtag selama periode 1 Januari - 31 Maret 2016 dan populasi survei adalah follower akun twitter @DitjenPajakRI, pengambilan sampel dengan teknik accidental sampling-convienence sampling sebanyak lima puluh orang. Data dikumpulkan melalui dokumentasi, kuisioner, dan observasi. Data dianalisis dengan menggunakan frekuensi tabulasi silang dan analisis regresi dengan bantuan program SPSS IBM 21. Hasil penelitian menunjukkan bahwa: 1) Tipe hashtag lebih dominan hasil retweet dan Fungsi Hashtag lebih banyak fungsi pengelompokkan; 2) Isi Hashtag lebih banyak bertopik kegiatan, bersifat informatif dan tautan berupa photo; 3) Tweet menggunakan Hashtag di sosial media dalam kegiatan penyuluhan online kesadaran membayar pajak memberikan pengaruh positif dan signifikan kepada attention, interest, search, action, dan share berdasarkan hasil uji model yang dilakukan, dengan memanfaatkan fitur yang ada di sosial media di harapkan membantu pemerintah dan lembaga non profit dalam kegiatan penyuluhan, dan kampanye kesadaran masyarakat.
\end{abstract}

Kata Kunci: Hashtag, Analisis Isi, Kesadaran Membayar Pajak.

\begin{abstract}
Social media continues to change how communication, one of the most unique yet understudied tools available on social media platforms is the hashtag. This research aims to determine : (1) type and function of hashtag used on@DitjenPajakRI account twitter, (2) content of hashtag employed on @DitjenPajakRI account twitter, (3) the effect of using the hashtag on @DitjenPajakRI account twitter for building tax paying awareness with AISAS model. The research was an descriptive research employing quantitative approaches. Quantitative content analyze as well as regression analysis were used to examine the hashtags variable within AISAS model. A Total of 51 hashtag from the periode of 1 january to 31 march was analyzed. The population was followers of @DitjenPajakRI account twitter, and the 50 samples were chosen using the accidental convienence sampling technique. The data were collected using documentation techniques, questionnaires, and observation. The data were then analyzed using the regression analysis and cross tabulation frequency helped by the SPSS IBM 21. The research results reveal that (1) the types of hashtag was dominantly a result of retweeted and the function of hashtags was predominantly category function; (2) the majority of hashtag content were event topic, informative characteristic, and photo link; (3) tweet that employed hashtag on social media regarding taxpaying had a positive and significant effect on online advocacy
\end{abstract}


program on attention, interest, search, action, and share based on model examination test. With the application of existing feature on social media, this will benefit the government as well as non-profit organizationfor conducting advocacy and community awareness campaign.

Keywords: Hashtags, content analysis, taxpaying awareness

\section{PENDAHULUAN}

Pesatnya perkembangan teknologi dalam beberapa dekade terakhir membawa banyak dampak ke berbagai sektor, salah satunya di sektor media dimana penyampaian dan pertukaran pesan dihadirkan melalui teknologi. Tidak dapat dipungkiri lagi bahwa teknologi, era baru dalam media terbentuk. Telah hadir wujud baru dari media massa yang dinamakan new media. Platform Sosial media mendominasi diskusi dari advokasi online karena mudah digunakan dan kemampuan untuk masuk ke dalam jaringan peer to peer untuk menyebarkan pesan penyuluhan (Goldkind \& McNutt, 2014; Guo \& Saxton, 2014).

Sumber penerimaan Negara terbesar dalam struktur Anggaran Pendapatan dan Belanja Negara (APBN) adalah penerimaan pajak. Pajak merupakan sumber pendapatan Negara terbesar. Kontribusinya mencapai $70 \%$ di antara Sumber alam, Badan Usaha Milik Negara (BUMN) maupun pinjaman luar negeri (Amir, 2013). Dari tahun ke tahun, penerimaan pajak yang ditargetkan selalu meningkat. Untuk mewujudkan hal tersebut, kesadaran masyarakat dalam memenuhi kewajiban perpajakan sangat diperlukan. Membangkitkan kesadaran dengan menginformasikan situasi kepada masyarakat sehingga mereka sadar akan isu-isu perpajakan, merupakan langkah awal untuk melibatkan masyarakat dalam isu-isu melalui kampanye, advokasi, dan sosialisasi. Menggunakan media baik media konvensional ataupun media digital merupakan salah satu cara yang paling efektif untuk membangkitkan kesadaran publik dan menyebarkan pesan-pesan perpajakan.

Wilayah media sosial merupakan hal baru yang harus diperhatikan ketika akan melakukan kegiatan strategi penyuluhan/kampanye. Media sosial merujuk pada sebuah tempat dimana konten, opini, sudut pandang dan media dapat langsung dibagikan kepada orang lain. Yang menjadi inti dari media sosial adalah lebih kepada hubungan dan koneksi antar manusia dan organisasi yang mereka ikuti
(Erwei, 2011). Berbagai tempat yang disebut media sosial antara lain Blog, Facebook, Twitter, myspace, dan situs jejaring sosial lainnya memudahkan seseorang untuk menyampaikan informasi dan berkomunikasi dengan sesama penggunanya (Kaplan \& Haenlin, 2009).

Dengan jumlah pengguna sosial media yang besar merupakan potensi untuk menyampaikan informasi tentang kebijakan pemerintah juga besar dengan biaya murah namun penggunaan social media oleh organisasi pemerintah masih minim dan dibutuhkan strategi untuk memaksimalkannya, salah satunya penggunaan fasilitas alat hashtags pada twitter (Bruns \& Burgess, 2013). Framework tersebut dibuat agar institusi pemerintah dapat menggunakan media sosial untuk berkomunikasi dengan masyarakat dengan langsung secara efektif. Menjadi suatu hal yang menarik disini ketika medium ini diterapkan pada perusahaanperusahaan non-profit ataupun organisasi kemanusiaan atau pemerintahan.

Beberapa penelitian sebelumnya telah fokus pada adopsi dan penggunaan sosial media diantara para praktisi dalam pekerjaan humas. Ada kecenderungan dalam memanfaatkan sosial media Twitter sebagai alat pembangun relasi antara organisasi dan publik Dengan perkenalan dari tiap teknologi baru, penelitian telah menunjukkan bahwa humas secara perlahan mengadopsi media baru (Edman, 2007). Penelitian ini juga menggambarkan bahwa praktisi humas cepat mengadopsi media baru, menemukan praktisi humas terlihat nyaman dengan alat yang telah muncul seperti email dan berargumen bahwa teknologi baru ini membuat keinstanan penerimaan dan penyebaran informasi (Eyrich et al., 2008).

Dengan adopsi cepat dan luas dari platform media sosial, semakin banyak literatur sekarang mulai mengeksplorasi pertemuan media sosial dan advokasi. Studi awal melihat adopsi, atau apakah advokasi organisasi nirlaba yang menggunakan alat media sosial (Bortree \& Seltzer, 2009). Gelombang berikutnya 
dieksplorasi persepsi manajer media sosial untuk pekerjaan advokasi (Obar et al., 2012). Seiring dengan tantangan potensi menggunakan alat media sosial (Goldkind \& McNutt, 2014). Penelitian juga telah mengeksplorasi bagaimana organisasi ini menggunakan media sosial untuk pekerjaan advokasi (Guo \& Saxton, 2014). Mereka menemukan banyak dari advokasi organisasi tidak menggunakan facebook untuk memfasilitasi dialog.

Penelitian ini bertujuan untuk mengetahui bagaimana pengaruhnya penggunaan hashtags dengan pesan kesadaran membayar pajak dalam kegiatan penyuluhan online. Penelitian ini menginformasikan teori dan praktik tentang bagaimana pemerintah dapat menggunakan platform sosial media untuk upaya kegiatan penyuluhan kebijakan publik/penyadaran masyarakat dan mengelola komunitas.

\section{BAHAN DAN METODE Obyek dan Rancangan Penelitian}

Penelitian ini merupakan penelitian kuantitatif dengan metode survei, yaitu penelitian dimana informasi dikumpulkan dari responden follower akun twitter @ DitjenPajakRI dengan menggunakan kuesioner. Jenis penelitian yang dilakukan adalah menggunakan riset deskriptif cross sectional dimana pengumpulan data mengenai sampel yang telah ditentukan dari elemen populasi diambil hanya satu kali saja. Penelitian ini menggunakan online survey yang dikeluarkan Google serta disebarkan melalui media sosial yaitu twitter.

\section{Sumber Data dan Teknik Pengumpulan Data}

Sumber data yang digunakan dalam penelitian ini adalah data primer dan juga data sekunder. Data primer digunakan untuk menguji hipotesis sedangkan data sekunder digunakan sebagai landasan teori yang memperkuat hipotesis. Untuk penelitian ini data primer yang merupakan populasi diperoleh dari kuesioner yang dibagikan kepada pengguna Twitter yaitu follower akun @DitjenPajakRI. Kemudian diajukan pertanyaan yang berkaitan dengan penggunaan hashtag dan pengaruhnya kepada wajib pajak dengan menggunakan Teori AISAS. Untuk data sekunder di peroleh melalui akun twitter DJP berupa tweet yang mengandung hashtag. Teknik pengambilan sampel yang digunakan accidental sampling - convienence sampling, dengan menyebar kuesioner melalui google document yang dianalisis kembali 50 kuesioner. Kemudian diajukan pertanyaan yang berkaitan dengan penggunaan hashtag di media sosial twitter dan pengaruhnya membangun kesadaran membayar pajak dengan menggunakan model AISAS variabel yang digunakan dalam penelitian ini adalah hashtag pada akun twitter, Attention, Interests, Search, Action, Share.

\section{Instrument Penelitian}

Pada survei yang menjadi instrument penelitian adalah kuesioner yang dibagikan ke follower akun@DitjenPajakRI.

\section{Analisis Data}

Teknik analisa data yang akan digunakan peneliti dalam penelitian ini analisis regresi, rangkaian regresi digunakan untuk menentukan hubungan antara penggunaan hashtag dan efektifitas pesan organisasi.

\section{Teknik Pengujian Validitas dan Realibilitas}

Untuk survei digunakan adalah analisis faktor untuk mengetahui serta menguji validitas dan realibilitas dari sample. Uji Validitas dilakukan dengan melihat nilai KMO, Bratlett Test of Spherericty, Anti-Image, Correlation dan Component matrix. Pada KMO nilai harus lebih besar atau sama dengan 0.5 , nilai signifikansi BTS lebih kecil atau sama dengan 0.05 dan nilai MSA yang berasal dari anti image correlation harus lebih besar atau sama dengan 0.5. Uji validitas dilakukan dengan menggunakan SPSS 21 IBM dengan melihat nilai yang muncul pada hasil pengolahan untuk menyatakan bahwa butir pertanyaan dalam kuesioner adalah benar.

Dari hasil uji validitas yang menggunakan analisis faktor, maka dapat diketahui tingkat validasi dari setiap konstruk yang akan dipergunakan untuk analisa selanjutnya. Kemudian tahap pengujian selanjutnya adalah menggunakan realibilitas yakni menguji instrument atau jenis pertanyaan dalam kuesioner yang apabila digunakan beberapa kali untuk mengukur objek yang sama, akan menghasilkan nilai (data) yang sama. Nilai dari Cronbach Alpha yang baik adalah bernilai lebih dari atau sama dengan 0.6, sehingga bisa dikatakan konstruksi tersebut reliabel. 


\section{HASIL}

\section{Karakteristik Responden}

Hasil penelitian memperlihatkan karakteristik responden yang menjadi sampel penelitian ini. Sebagian besar responden berjenis kelamin pria 36 atau $72 \%$ dibanding wanita. Usia lebih dominan pada 27 - 34 tahun sebanyak 21 atau $42 \%$. Berdasarkan aspek sosial ekonomi yang dinilai berdasarkan tingkat pendidikan, pekerjaan dan penghasilan responden. Menunjukkan sebagian besar responden tingkat pendidikan mayoritas sarjana 29 orang atau $58 \%$. Lebih dari $60 \%$ responden bekerja sebagai pegawai negeri sipil dengan jumlah penghasilan diatas 9 juta tiap bulannya (30\%).

\section{Hasil Uji Hipotesis dan Analisis Persamaan Regresi}

Seperti yang diketahui sebelumnya pengujian hipotesis dilakukan berdasarkan hasil dari nilai signifikansi regresi linier. Pada tabel 1 merupakan hasil yang diperoleh berdasarkan olahan melalui perangkat SPSS. Untuk persamaan regresi dari Hipotesis yang digunakan pada penelitian ini adalah sebagai berikut:

H1 : Tweet penyuluhan menggunakan Hashtag di sosial media mempunyai pengaruh positif terhadap attention seseorang kepada informasi yang disampaikan.

Persamaan regresi untuk Sub Model 1

$$
\mathrm{Y}=1.977+0.684 \mathrm{X}_{1}+0.096
$$

Dari hasil pengolahan data dapat dinyatakan bahwa hipotesa 1 dapat diterima karena nilai signifikansi dari t hitung lebih kecil dari 0.05 (seperti yang tertera pada tabel 1), kemudian interpretasi dari sub model 1 adalah terjadi pengaruh positif antara penggunaan Hashtag pada sosial media untuk melakukan kegiatan penyuluhan atau kampanye dengan attention dari follower untuk memperhatikan tweet /kicauan tersebut.

$\mathrm{H} 2$ : Tweet penyuluhan menggunakan Hashtag di sosial media mempunyai pengaruh positif terhadap Interests seseorang kepada informasi yang disampaikan.

Persamaan regresi untuk Sub Model 2

$$
\mathrm{Y}=2.532+0.688 \mathrm{X}_{2}+0.082
$$

Dengan hasil tersebut dapat dinyatakan bahwa hipotesa 2 dapat diterima karena nilai signifikansi dari t hitung lebih kecil 0.05 (seperti yang tertera pada tabel 1). Kemudian interpretasi dari sub model 2 adalah bahwa terjadi pengaruh positif antara penggunaan Hashtag untuk menyampaikan informasi atau kampanye/penyuluhan online di sosial media twitter, terhadap interest seseorang kepada informasi yang disampaikan.

H3: Tweet menggunakan Hashtag di sosial media mempunyai pengaruh positif kepada follower untuk mencari informasi pajak tersebut lebih lanjut melalui media-media seperti website, blog, dan sebagainya.

Persamaan regresi untuk sub model 3 adalah:

$$
\mathrm{Y}=2,517+0.660 \mathrm{X}_{3}+0.091
$$

Dengan hasil tersebut dapat dinyatakan bahwa hipotesa 3 dapat diterima karena nilai signifikansi dari t hitung lebih kecil dari 0.05. (seperti yang tertera pada tabel 1) kemudian untuk interpretasi dari sub model 3 adalah terjadi pengaruh positif antara penggunaan Hashtag pada tweet/kicauan dalam penyuluhan online di sosial media terhadap pencarian informasi lebih lanjut oleh follower atas informasi yang disampaikan tersebut.

H4 : Tweet menggunakan Hashtag di sosial media mempunyai pengaruh positif terhadap keinginan untuk melakukan pelaporan SPT dan pembayaran pajak.

Persamaan regresi untuk sub model 4 adalah:

$$
\mathrm{Y}=2.182+0.701 \mathrm{X}_{4}+0.091
$$

Dengan hasil tersebut dapat dinyatakan bahwa hipotesa 4 dapat diterima karena nilai signifikansi dari t hitung lebih kecil dari sub model 4 adalah terjadi pengaruh positif antara tweet yang menggunakan Hashtag di sosial media terhadap kegiatan action yang dilakukan oleh follower.

H5 : Tweet menggunakan Hashtag di sosial media berpengaruh positif terhadap seseorang untuk membagikan pengalaman setelah melaporkan dan membayar pajak yang dikampanyekan tersebut melalui sosial media. 
Persamaan regresi untuk sub model 5 adalah:

$$
\mathrm{Y}=2.479+0.741 \mathrm{X}_{5}+0.072
$$

Dengan hasil regresi tersebut dinyatakan bahwa hipotesa 5 dapat diterima karena nilai signifikansi dari t hitung lebih kecil dari 0.05. (seperti yang tertera pada tabel 1). kemudian interpretasi dari hipotesa 5 adalah terjadi pengaruh positif antara iklan/kampanye/penyuluhan menggunakan Hashtag di sosial media terhadap kegiatan responden dalam membagikan pengalamannya ketika melihat tweet tersebut.

\section{Bagaimana Pengaruh penggunaan Hashtag di sosial media terhadap Attention seseorang atas informasi yang disampaikan?}

Dari hasil uji regresi hipotesa 1 adalah terjadi pengaruh positif antara penggunaan Hashtag pada sosial media untuk melakukan kegiatan penyuluhan atau kampanye dengan attention dari follower untuk memperhatikan tweet /kicauan tersebut.

Dari hasil kuesioner didapatkan hasil dimana setiap ada Hashtag yang semakin menarik akan meningkatkan attention untuk tweet/kicauan pajak di sosial media. Sebanyak 50 responden mengatakan bahwa mengetahui adanya informasi pajak dari sosial media. Selain itu juga jika dilihat jawaban responden terlihat bahwa sebagian besar (34 responden) atau sebesar $68 \%$ setuju bahwa kegiatan penyuluhan atau kampanye dengan menggunakan Hashtag di sosial media membuat dirinya memperhatikan tweet/kicauan akun @DitjenPajakRI.

Bagaimana Pengaruh penggunaan Hashtag di sosial media terhadap Interest seseorang atas informasi yang disampaikan?

Dari hasil uji regresi hipotesa 2 adalah bahwa terjadi pengaruh positif antara penggunaan Hashtag untuk menyampaikan informasi atau kampanye/penyuluhan online di sosial media twitter, terhadap interest seseorang kepada informasi yang disampaikan. Dibuktikan pada pengolahan data dimana setiap penambahan Hashtag yang menarik di sosial media dapat meningkatkan interest terhadap tweet/kicauan.

Dari hasil kuesioner didapatkan hasil bahwa sebagian besar responden memberikan jawaban diwilayah yang positif bahwa tweet yang menggunakan Hashtag tersebut memberikan pengaruh terhadap seseorang untuk memperhatikan informasi tentang pajak.

Bagaimana Pengaruh penggunaan Hashtag di sosial media terhadap Search seseorang atas informasi yang disampaikan?

Dari hasil uji regresi hipotesa 3 adalah bahwa terjadi pengaruh positif antara penggunaan Hashtag pada tweet/kicauan dalam penyuluhan online di sosial media terhadap pencarian informasi lebih lanjut oleh follower atas informasi yang disampaikan tersebut.

Dari hasil kuesioner jika dilihat pada jawaban responden sangat setuju dan setuju sebanyak 54\% sebagian besar melakukan pencarian informasi selanjutnya ketika ada tweet yang menggunakan Hashtag di sosial media terlihat oleh mereka.

Bagaimana Pengaruh penggunaan Hashtag di sosial media terhadap Action seseorang atas informasi yang disampaikan?

Dari hasil uji regresi hipotesa 4 terjadi pengaruh positif antara tweet yang menggunakan Hashtag di sosial media terhadap kegiatan action yang dilakukan oleh follower. Sehingga jika menambah Hashtag yang menarik di sosial media akan bisa meningkatkan kepatuhan pelaporan SPT dan Pembayaran pajak yang dilakukan oleh wajib pajak.

Dari hasil kuesioner responden sebanyak $56 \%$ sangat setuju dan setuju dominan berada pada wilayah yang positif ketika mereka melihat informasi pajak dengan lebih lengkap kemudian tertarik untuk melaporkan SPT dan membayar pajak tepat waktu.

Bagaimana Pengaruh penggunaan Hashtag di sosial media terhadap Share seseorang atas informasi yang disampaikan?

Dari hasil uji regresi hipotesa 5 terjadi pengaruh positif antara iklan/kampanye/ penyuluhan menggunakan Hashtag di sosial media terhadap kegiatan responden dalam membagikan pengalamannya ketika melihat tweet tersebut.

Dari hasil kuesioner jika dilakukan penambahan Hashtag yang menarik di sosial media bisa meningkatkan kemauan dari follower untuk membagikan pengalamannya di sosial 
media. Hal tersebut didukung oleh pilihan responden dimana sebagian besar berada pada wilayah pilihan setuju sebanyak $80 \%$ untuk membagikan pengalamannya di sosial media.

\section{PEMBAHASAN}

Pada penelitian ini menunjukkan penggunaan hashtag berpengaruh terhadap pesan kesadaran membayar pajak, dengan menggunakan model AISAS bahwa responden pada tahap Attention sampai pada tahap Share mayoritas aktif ataupun setuju proses melakukan sebuah keinginan untuk melaporkan dan membayar pajak. Jika follower tersebut melihat iklan/kampanye/penyuluhan melalui sosial media sudah dapat dibuktikan dengan metode AISAS. Dengan melihat follower @DitjenPajakRI yang terjaring dalam kuesioner ini, dengan program iklan/kampanye/penyuluhan menggunakan Hashtag di sosial media dimana Hashtag tersebut melakukan update tweet berisi iklan/kampanye/penyuluhan pajak dan didalamnya terdapat tautan yang bisa menjadi tempat referensi untuk pencarian informasi berikutnya.

Pada uji hipotesis diatas sesuai dengan penelitian menyatakan bahwa penggunaan Integrated Marketing Communication dengan memanfaatkan new media dengan bantuan alat Hashtag yang ada di sosial media berpengaruh terhadap ketertarikan dan keingintahuan wajib pajak terhadap iklan/kampanye/penyuluhan online yang diberikan, kemudian berpengaruh terhadap keinginan untuk mencari informasi selanjutnya melalui tautan yang ada disana (Alyssa, 2008).

Setelah mengetahui informasi secara lebih lengkap, follower bisa langsung mengetahui informasi tentang pajak, pelaporan online melalui e-filling dan pembayaran online melalui e-billing. Dan pada akhirnya follower yang telah melaporkan SPT tersebut akan memberikan pengalamannya melalui sosial media sehingga teman-temannya bisa membaca hasil dari pelaporan SPT dan pembayaran pajak tersebut.

Menurut teori elaboration likelihood model, penelitian akan sikap skeptical konsumen terhadap review dan rekomendasi yang tersedia secara online (baik itu tersedia pada forumforum, blog, maupun sosial media) menyatakan bahwa konsumen akan melakukan pencarian lebih dalam lagi ketika sudah tertarik atau timbul atensi terhadap iklan/kampanye/penyuluhan tersebut (Sher \& Lee, 2009).

Follower akan melakukan pencarian secara seksama dan memperhatikan lebih detail tentang informasi tentang pajak tersebut, sehingga jika dikolaborasikan dengan teori AISAS maka kesadaran wajib pajak untuk melakukan pelaporan dan pembayaran pajak tepat waktu dan benar melalui aplikasi efiling dan ebiling dari Direktorat Jenderal Pajak.

Pemilihan Hashtag yang menarik juga sangat penting untuk meningkatkan atensi/perhatian serta ketertarikan terhadap iklan/kampanye/penyuluhan di sosial media (Kywe et al., 2012). Hal ini terlihat dari hasil kuesioner dimana Hashtag yang dikenal dan diketahui meningkatkan kesadaran membayar pajak adalah \#efiling \#ebiling, \#ayolaporpajak. Jika peluang untuk dibaca semakin banyak karena faktor dari Hashtag, maka semakin besar peluang untuk bisa mempengaruhi wajib pajak untuk melakukan pencarian lebih lanjut sekaligus menumbuhkan kesadaran membayar pajak untuk melakukan pelaporan SPT dan pembayaran pajak sehingga pada akhirnya muncul pembagian pengalaman yang dilakukan oleh follower di sosial media.

Menurut teori internet word of mouth, ketika followers juga turut serta dalam melakukan sharing pengalaman, maka follower tersebut juga-lah yang akan menjadi agent campaign dari penyuluhan kesadaran membayar pajak tersebut, sesuai dengana studi literature sebelumnya mengenai kepercayaan seseorang terhadap pendapat di ranah dunia maya (Zhang et al.,2010).

\section{KESIMPULAN DAN SARAN}

Hasil penelitian ini didapatkan bahwa tweet menggunakan Hashtag di sosial media dalam kegiatan penyuluhan online kesadaran membayar pajak memberikan pengaruh positif kepada attention, interest, search, action, dan share berdasarkan hasil uji model yang dilakukan sebelumnya. Dari semua konstruk hubungan antara Hashtag di sosial media terhadap search di sosial media memberikan hasil yang paling kecil. Sementara itu yang paling besar hubungannya adalah antara Hashtag dengan share seseorang terhadap tweet dalam kegiatan penyuluhan kesadaran membayar pajak 
online tersebut. Untuk organisasi strategi pada kegiatan penyuluhan dan kampanye di media sosial, tweet akan mendapat retweet jika menggunakan hashtag unik. Menjaring audiens ke dalam gerakan atau dialog lebih disukai untuk dibagi ke yang lain.

\section{DAFTAR PUSTAKA}

Alyssa G. (2008). Integrated Marketing Communication Anticipating the 'Age of Engage'. International Journal.

Amir H. (2013). "The Impact of the Indonesian Income Tax Reform: A CGE Analysis". Economic Modelling 31: 492-501.

Bortree D. \& Seltzer T. (2009). "Dialogic strategies and outcomes: An analysis of environmental advocacy groups"Facebook profiles". Public Relations Review, 317-319.

Bruns A. \& Burgess J.E. (2011). The use of Twitter hashtag in the formation of ad hoc publics. Paper presented at the $6^{\text {th }}$ European Consortium for Political Research General Conference, University of Iceland, Reykvjavik.

Edman H. (2007). Twittering To The Top: A Content Analysis Of Corporate Tweets To Measure Organization-Public Relationships. Tesis. Baton Rouge: Lousiana State University.

Erwei M.A. (2011). Influence of Integrated Marketing Communication on Advertising Operation. Journal of interactive advertising, vol 12 (1).

Eyrich N., Padman M., \& Sweetser K. (2008). $P R$ practitioners use of social media tools and communication technology. Public Relations Review, 34(4): 412-414.

Goldkind L. \& McNutt J. G. (2014). Social media and social change: Nonprofits and using social media strategies to meet advocacy goals. In A.M. Jose Antonio \& L.-C. Ana Maria (Eds.), ICT management in non-profit organizations (pp. 56-72) Hershey, PA, USA: IGI Global.

Guo C. \& Saxton G.D. (2014). Tweeting social change: How social media are changing nonprofit advocacy. Nonprofit and Voluntary Sector Quarterly, 43(1):57-79.

Kaplan A.M. \& Haenlin M. (2009). User of the world, Unite! The challaenges and opportunities of social media. Elsevier.

Kywe S. M., Hoang T. A., Lim E. P., \& Zhu F. (2012). On recommending hashtags in Twitter networks. Social Informatics, 337350.

Obar J.A., Zube P., \& Lampe C. (2012). Advocacy 2.0: An analysis of how Advocacy grups in the United States perceive and use social media as tools for facilitating civic engagement and collective action. Journal of information policy, 1-25.

Sher P.J. \& Lee S. (2009)."Consumer Skepticism and Online reviews: An Elaboration Likelihood Model Perspective”. Social Behaviour\&Personality: An International Journal 37(1):137.

Zhang, Yaowem, \& Tingjielv. (2010). Analysis of the relationship between involvement and the internet word-of-mouth. School of Economic and Management, Beijing. 
Tabel 1 : Hasil Analisis Hipotesis dan Persamaan Regresi

\begin{tabular}{lccc}
\hline \multicolumn{1}{c}{ Hipotesis } & $\begin{array}{c}\text { Sig t } \\
\text { Value }\end{array}$ & $\begin{array}{c}\text { b } \\
\text { Value }\end{array}$ & $\begin{array}{c}\text { R-square } \\
\text { value }\end{array}$ \\
\hline $\begin{array}{l}\text { H1 I Independen variabel } \\
\begin{array}{l}\text { Penggunaan Hashtag, dependen } \\
\text { variable attention }\end{array}\end{array}$ & .000 & 0.688 & 0.473 \\
$\begin{array}{l}\text { H2 I Independen variabel } \\
\text { Penggunaan Hashtag, dependen } \\
\text { variable Interest }\end{array}$ & .000 & 0.668 & 0.473 \\
$\begin{array}{l}\text { H3 I Independen variabel } \\
\begin{array}{l}\text { Penggunaan Hashtag, dependen } \\
\text { variable search }\end{array}\end{array}$ & .000 & 0.660 & 0.435 \\
$\begin{array}{l}\text { H4 I Independen variabel } \\
\text { Penggunaan Hashtag, dependen } \\
\text { variable } \text { Action }\end{array}$ & & & \\
$\begin{array}{l}\text { H5 I Independen variabel } \\
\text { Penggunaan Hashtag, dependen } \\
\text { variable Share }\end{array}$ & .000 & 0.701 & 0.491 \\
\hline \multicolumn{1}{c}{ Sumber: data primer diolah 2016} & \\
\hline
\end{tabular}

